\title{
Evaluation of the neuroprotective efficiency of sodium hydrosulfide in neonatal rats with the induced hypoxic- ischemic encephalopathy model
}

\author{
Cebeci $\mathrm{B}^{1}$, Yalinbas $\mathrm{EE}^{2}$, Akcilar $\mathrm{R}^{3}$, Metineren $\mathrm{H}^{4}$ \\ Kutahya Health Sciences University, Medical Faculty, Department of Neonatology, Kutahya, Turkey. \\ esinylnbs@gmail.com
}

\begin{abstract}
AIMS: Hypoxic ischemic encephalopathy is one of the main causes of neonatal deaths.

The objective of this study was to evaluate the neuroprotective effect of antioxidant and anti-inflammatory properties of sodium hydrosulfide (NaHS) in neonatal rats with hypoxic ischemic encephalopathy, as well as its effect on neuronal apoptosis through histopathological and biochemical tests.

METHODS: Forty-seven-day-old rats with induced hypoxia-ischemia $(\mathrm{HI})$ were randomly separated into four groups. Half an hour after the induction of hypoxic-ischemia, serum physiological (SF), $50 \mu \mathrm{mol} / \mathrm{kg} \mathrm{NaHS}$, or $100 \mu \mathrm{mol} / \mathrm{kg} \mathrm{NaHS}$ were intraperitoneally given to the rats.

RESULTS: Apoptotic cells in the brain tissue of rats in $\mathrm{HI}+\mathrm{NaHS} 50 \mu \mathrm{mol} / \mathrm{kg}$, and $\mathrm{HI}+\mathrm{NaHS} 100 \mu \mathrm{mol} / \mathrm{kg}$ groups decreased compared to $\mathrm{HI}$ group $(p=0.00)$. While $\mathrm{HI}+\mathrm{NaHS} 50 \mu \mathrm{mol} / \mathrm{kg}$ and $\mathrm{HI}+\mathrm{NaHS} 100 \mu \mathrm{mol} /$ $\mathrm{kg}$ groups yielded no difference in TNF- $\alpha$, IL-6, and iNOS levels as compared to the HI group, an increase in NGF was detected in the $50 \mu \mathrm{mol} / \mathrm{kg}$ and $100 \mu \mathrm{mol} / \mathrm{kg} \mathrm{NaHS}$ groups $(p=0.34, p=0.24, p=0.26, p=0.026$, $p=0.017)$. When TOS, TAS and OSI levels were compared, an increase in TAS and OSI and a decrease in TOS were observed in the treatment groups as compared to HI group.

CONCLUSIONS: NaHS given to hypoxic-ischemic encephalopathy model significantly decreased apoptosis in neurons and had a neuroprotective efficacy with an increase in NGF levels (Tab. 1, Fig. 3, Ref. 25). Text in PDF www.elis.sk

KEY WORDS: hypoxic-ischemic encephalopathy, neonatal, NaHS, NGF, antioxidant.
\end{abstract}

\section{Introduction}

Presenting with impaired consciousness or convulsions and characterized by respiratory depression and hypotonia, neonatal encephalopathy (NE) is defined as a heterogeneous clinical syndrome occurring in the early postnatal period in rats born in and after the 35th gestational week. NE may have many different causes, but birth asphyxia and neonatal hypoxic encephalopathy are responsible for most cases (1). The numbers of cases with irreversible damage and death following perinatal asphyxia are high, and thus, neuroprotective strategies preventing damage development are emphasized.

As many studies have proven, therapeutic hypothermia is neuroprotective, and as such, it is the standard treatment for term

${ }^{1}$ Department of Pediatrics, Batman State Hospital, Batman, Turkey, ${ }^{2}$ University of Kutahya Health Sciences, Faculty of Medicine, Department of Neonatology, Kutahya, Turkey, ${ }^{3}$ University of Kutahya Health Sciences, Faculty of Medicine, Department of Physiology, Kutahya, Turkey, and ${ }^{4}$ University of Kutahya Health Sciences, Faculty of Medicine, Department of Pathology, Kutahya, Turkey

Address for correspondence: E. Esin Yalinbas, MD, Kutahya Health Sciences University, Medical Faculty, Department of Neonatology, Kutahya, Turkey

Phone: +905333776845, Fax: +902742652285 and late preterm neonates with encephalopathy (2). Additional strategies to increase the neuroprotective effects of hypothermia are targeted in continuing studies (3). To prevent the formation of free oxygen radicals, agents removing free oxygen radicals (selenium, vitamin $\mathrm{E}, \mathrm{N}$-acetyl cysteine, and ascorbic acid), stem cell transfer, dexamethasone, calcium channel blockers, magnesium sulfate and antiepileptic drugs can be used (4). Endogenous hydrogen sulfide (H2S) is formed in the brain due to cystathionine b-synthase catalysis of cysteine. H2S, in physiological concentrations, is effective for preventing and removing different oxidizing materials in the nervous system and thus increases neuronal protection, and decreases oxidative-stress-related tissue damage. Sodium hydrosulfide (NaHS) is an $\mathrm{H} 2 \mathrm{~S}$ transmitter and can directly transform into H2S in serum. Many studies have shown that NaHS can decrease damage which may develop in a target organ during ischemia-reperfusion in the myocardium, kidney, liver, and large intestines. It also has anti-inflammatory, antiapoptotic, and antioxidant characteristics. The neuroprotective and antioxidant efficacies of NaHS in cerebral ischemia damage have been observed but incompletely clarified $(5,6)$. Therefore, the objective of this study was to evaluate the neuroprotective effect of antioxidant and anti-inflammatory properties of NaHS, in neonatal rats with hypoxic ischemic encephalopathy, as well as its effect on neuronal apoptosis through histopathological and biochemical tests. 


\section{Materials and methods}

Animals

This study was approved by the Ethics Committee of Animal Care and Usage of Kutahya Health Sciences University, Kutahya, Turkey. Sprague-Dawley rats, at 16-18 days of pregnancy, were kept separately in a barrier facility at a temperature of $25.0 \pm 1.0$ ${ }^{\circ} \mathrm{C}$ and relative humidity of $60 \pm 5 \%$ with food and water $\mathrm{ad} l i$ bitum, under a 12/12 h light/dark cycle. These conditions were designed to prevent exposing the animals to bright light or noise. Pups weighing 13-19g were selected on postnatal day 7 (P7).

\section{Hypoxic ischemic (HI) brain injury model}

The HI brain injury model in neonatal rats was established according to the method detailed by Rice-Vannucci (7). P7 rat pups were anesthetized by isoflurane inhalation. After anesthesia, the necks of the rat pups, using standard sterile techniques, were draped and prepared. In a supine position, the left common carotid artery was ligated with a 5-0 silk suture. Rats were exposed to hypoxia ( $8 \%$ oxygen concentration and $92 \%$ nitrogen) using standard published protocols, for $2 \mathrm{~h}$ at $37^{\circ} \mathrm{C}$. The flow rate was monitored continuously in the chamber. After exposure to hypoxia, all animals were monitored closely for any signs of distress, failure to thrive, infection, or serious disability. After hypoxia, animals were assessed and returned to their mothers.

\section{Sodium hydrosulfide (NaHS) administration and animal group-} ing

Pups from each litter were randomly assigned to four groups $(\mathrm{n}=9)$ as follows:

1. Control group $(C)$ : In the control group, rat pups were randomly chosen from the same litters of HI rats, and only the skin incision was performed to isolate and expose the common carotid artery; neither ligation, nor hypoxia, were administered to these animals.

2. HI group: HI brain injury was induced.

3. $\mathrm{HI}+$ sodium hydrosulfide $50 \mu \mathrm{mol} / \mathrm{kg}(\mathrm{HI}+\mathrm{NaHS} 50 \mu \mathrm{mol} / \mathrm{kg})$ group: NaHS was administrated $30 \mathrm{~min}$ after HI brain injury by intraperitoneal (ip) injection in a dose of $50 \mu \mathrm{mol} / \mathrm{kg}(8)$.

4. $\mathrm{HI}+$ sodium hydrosulfide $100 \mu \mathrm{mol} / \mathrm{kg}(\mathrm{HI}+\mathrm{NaHS} 100 \mu \mathrm{mol} / \mathrm{kg})$ group: NaHS was administered 30 min after HI brain injury by an ip dose of $100 \mu \mathrm{mol} / \mathrm{kg}(9)$. phosphate nick-end labelling (TUNEL) method. The left hemisphere was stored at $-80^{\circ} \mathrm{C}$ until analyzed biochemically and via molecular biologic studies.

\section{Biochemical analyses}

The brain tissue extracted from the sacrificed animals was first placed in a phosphate buffer $(\mathrm{pH} 7,4)$. Briefly, the tissues were disrupted with a homogenizer (WiseTis, HG-15A, Korea). Later, the tissue samples were centrifuged at 7,800 $\mathrm{x}$ for $15 \mathrm{~min}$ at $+4{ }^{\circ} \mathrm{C}$. Total anti-oxidative status (TAS) and total oxidative status (TOS) levels, which are among the oxidative stress parameters, were measured using kits (Rell Assay, Gaziantep, Turkey) according to the manufacturer's protocol $(9,10)$. Changes in the absorbance of samples were measured at $530 \mathrm{~nm}$ and $660 \mathrm{~nm}$ using an ELISA microplate reader (Thermo Multiscan GO, 1510, Finland), and the results were expressed as mmol Trolox Eq/mg protein. The oxidative stress index (OSI) was defined by formula: OSI (arbitrary unit $)=[(\mathrm{TOS}, \mathrm{mmol} / \mathrm{L}) /(\mathrm{TAS}, \mathrm{mmol}$ Trolox equivalent $/ \mathrm{L}) / 100]$.

\section{RNA extraction and $c D N A$ synthesis}

Total RNA was extracted from the frozen brain tissue samples using the GeneJET RNA Purification Kit (Thermo, Cat No: \# K0732) according to the manufacturer's protocol. The purity and concentration of the extracted RNA was determined spectrophotometrically at $260 \mathrm{~nm}$ and $280 \mathrm{~nm}$ wavelengths (Maestro Nano Micro-Volume spectrophotometer, Maestrogen Inc., Las Vegas, NV). Complementary DNAs (cDNA) were synthesized from 1 $\mu \mathrm{g}$ of the total RNA using an EasyScript ${ }^{\mathrm{TM}}$ cDNA Synthesis Kit (abm) according to the manufacturer's instructions. The cDNAs were stored at $-20^{\circ} \mathrm{C}$ until used in the quantitative real-time polymerase chain reaction (qRT-PCR).

\section{Quantitative real-time PCR}

The mRNA levels of transforming growth factor-alpha (TNF- $\alpha$ ), interleukin 6 (IL-6), nerve growth factor (NGF), inducible nitric oxide synthase (iNOS), and the housekeeping gene beta-actin ( $\beta$-actin) were measured by qRT-PCR using a LightCycler 480 Real-Time PCR System (Roche Diagnostics, Germany). The specific primers for measuring target genes and $\beta$-actin were used, and the lengths for amplified products were as follows: $\beta$-actin (Sense: 5'-AGG CCA ACC GTG AAA AGA TG-3' and anti-sense: 5'-ACC AGA GGC ATA CAG GGA CAA-3', 100 bp);

\section{Sample collection}

Neonatal rats $(n=9$, in each group) were anesthetized with isoflurane inhalation $5 \mathrm{~h}$ after NaHS injections and then sacrificed. Brain tissue samples were collected in liquid nitrogen and rapidly dissected. Brain tissue was precisely divided into two hemispheres. The right hemisphere was kept in a $10 \%$ formalin solution for histological examination and analyzed for neuronal apoptosis using the terminal deoxynucleotidyl transferase-mediated deoxyuridine tri-
Tab. 1. Oxidative stress markers of brain tissue in all groups.

\begin{tabular}{lccccc}
\hline Groups & $\begin{array}{c}\mathrm{C} \\
(\mathrm{n}=9)\end{array}$ & $\begin{array}{c}\mathrm{HI} \\
(\mathrm{n}=9)\end{array}$ & $\begin{array}{c}\mathrm{HI}+\mathrm{NaHS} \\
50 \mu \mathrm{mol} / \mathrm{kg} \\
(\mathrm{n}=9)\end{array}$ & $\begin{array}{c}\mathrm{HI}+\mathrm{NaHS} \\
100 \mu \mathrm{mol} / \mathrm{kg} \\
(\mathrm{n}=9)\end{array}$ & $\mathrm{p}$ \\
\hline TAS $(\mathrm{mmol} / \mathrm{L})$ & $0.32 \pm 0.07^{\mathrm{a}}$ & $0.29 \pm 0.05^{\mathrm{b}}$ & $0.48 \pm 0.07$ & $0.65 \pm 0.11^{\mathrm{ab}}$ & 0.04 \\
TOS $(\mu \mathrm{mol} / \mathrm{L})$ & $14.4 \pm 0.77^{\mathrm{ab}}$ & $25.9 \pm 3.28^{\mathrm{ac}}$ & $20.7 \pm 0.80^{\mathrm{b}}$ & $17.5 \pm 1.77^{\mathrm{c}}$ & 0.000 \\
OSI & $4.78 \pm 0.97^{\mathrm{a}}$ & $15.9 \pm 4.08^{\mathrm{abc}}$ & $4.63 \pm 0.90^{\mathrm{b}}$ & $4.28 \pm 1.05^{\mathrm{c}}$ & 0.03 \\
\hline
\end{tabular}

p: shows the differences between all groups (Kruskal-Wallis test).

a,b,c $:$ in each line, the difference between the means with the same letters are significant, $\mathrm{p} \leq 0.05$ (Mann-Whitney U test).

Groups: Control (C; n=9), Hypoxic ischemia group (HI; n=9), Hypoxic ischemia + sodium hydrosulfide $50 \mu \mathrm{mol} / \mathrm{kg}$ group (HI+NaHS $50 \mu \mathrm{mol} / \mathrm{kg} ; \mathrm{n}=9$ ), Hypoxic ischemia + sodium hydrosulfide $100 \mu \mathrm{mol} / \mathrm{kg}$ group (HI+NaHS $100 \mu \mathrm{mol} / \mathrm{kg} ; \mathrm{n}=9$ ).

TAS - total anti-oxidative status, TOS - total oxidative status, OSI - oxidative stress index 

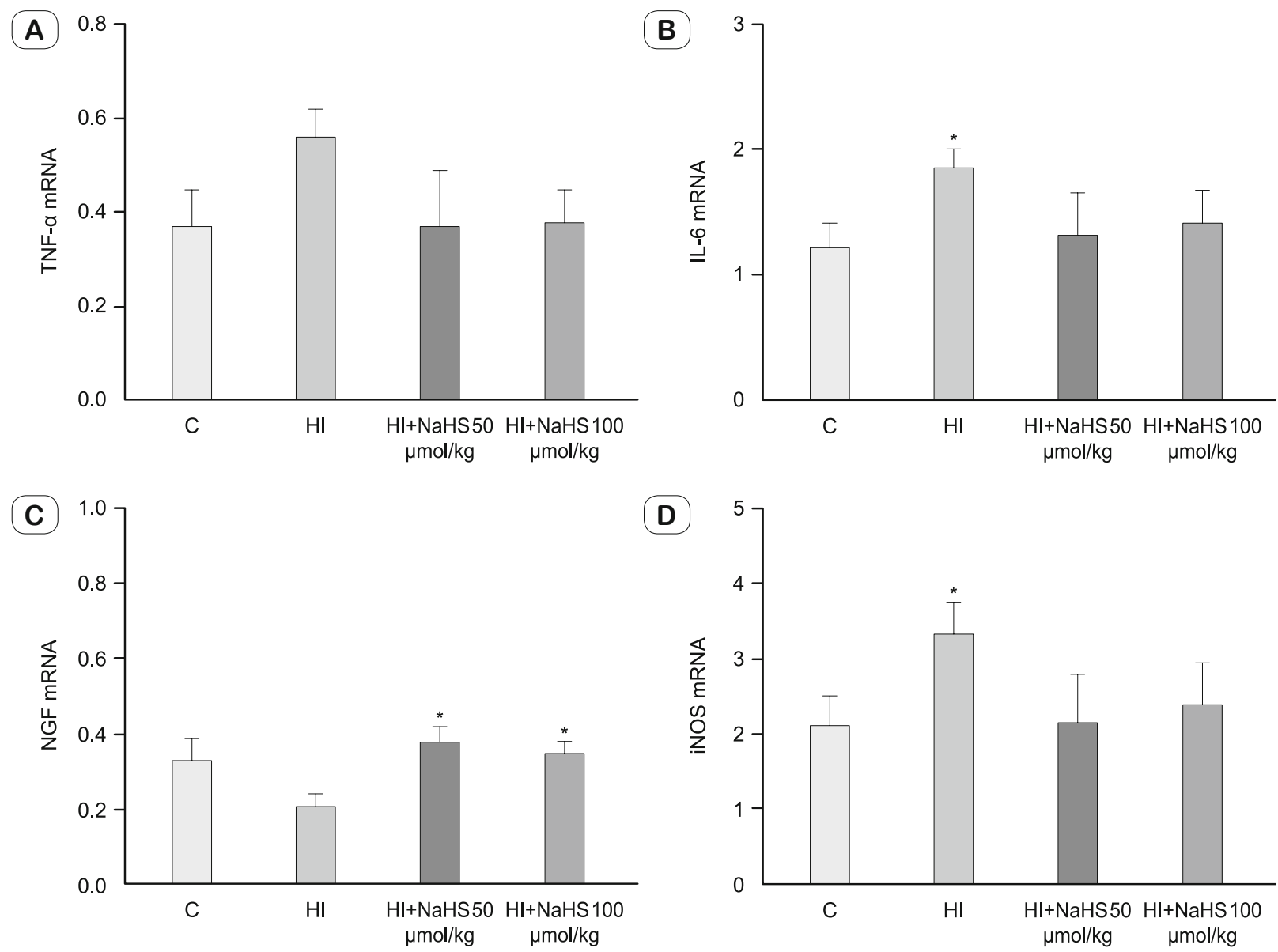

Fig. 1. Effect of NaHS on mRNA expression of TNF- $\alpha$, IL-6, NGF and iNOS: A; There were no significant differences in TNF- $\alpha$ gene mRNA expression levels in the brain tissues among C, HI, HI + NaHS $50 \mu \mathrm{mol} / \mathrm{kg}$, and HI + NaHS $100 \mu \mathrm{mol} / \mathrm{kg}$ groups (p >0.05). B; * shows significant difference between $\mathrm{C}$ and $\mathrm{HI}$ groups $(\mathrm{p} \leq \mathbf{0 . 0 5}$; Mann-Whitney $\mathrm{U}$ test). $\mathrm{C}$; * shows significant difference between $\mathrm{HI}$ and HI $+\mathrm{NaHS} 50$ $\mu \mathrm{mol} / \mathrm{kg}$ groups $(\mathrm{p} \leq \mathbf{0 . 0 5}$; Mann-Whitney $\mathrm{U}$ test), $\uparrow$ shows significant difference between $\mathrm{HI}$ and $\mathrm{HI}+\mathrm{NaHS} 100 \mu \mathrm{mol} / \mathrm{kg}$ groups $(\mathrm{p} \leq 0.05$; Mann-Whitney $U$ test). D; * shows significant difference between $\mathrm{C}$ and $\mathrm{HI}$ groups ( $\mathrm{p} \leq 0.05$; Mann-Whitney $\mathrm{U}$ test).

TNF- $\alpha$ (Sense: 5'-CCA CCA CGC TCT TCT GTC TAC-3' and anti-sense: 5'-GCT ACG GGC TTG TCA CTC G-3', 148 bp); IL-6 (Sense: 5'-CTT CCA GCC AGT TGC CTT CTT G-3' and anti-sense: 5'-TGG TCT GTT GTG GGT GGT ATC C-3', 109 bp); NGF (Sense: 5'-CCA AGG ACG CAG CTT TCT AT-3' and anti-sense: 5'-CTC CGG TGA GTC CTG TTG AA-3', 500 bp), and iNOS (Sense: $5^{\prime}$-TGT TGT AGC GCT GTG TGT CA-3' and anti-sense: 5'-CAC CTT GGA GTT CAC CCA GT-3', 126 bp). All PCR amplifications were performed in duplicate reactions and in the final volume of $20 \mu \mathrm{l}$ containing $5 \mu \mathrm{lDNA}, 0.6 \mu \mathrm{l}$ of specific primers, and $10 \mu$ of master mix SYBR green (EvaGreen Express qPCR MasterMix, abm, Canada) $3.8 \mu \mathrm{ddd}_{2} \mathrm{O}$ using the following protocol:

1. Pre-incubation at $95^{\circ} \mathrm{C}$ for $30 \mathrm{~s}$ to activate DNA Taq polymerase,

2. Forty two-step cycles with denaturation at $95{ }^{\circ} \mathrm{C}$ for $15 \mathrm{~s}$,

3. Annealing at $60^{\circ} \mathrm{C}$ for $60 \mathrm{~s}$,

4. Extension at $72{ }^{\circ} \mathrm{C}$ for $30 \mathrm{~s}$.
In addition, the no-template negative control $\left(\mathrm{H}_{2} \mathrm{O}\right)$ was routinely run in every PCR. The melting curve was examined at the end of the amplification process to ensure the specificity of PCR products. The expression levels of target genes (TNF- $\alpha$, IL- 6 , NGF, iNOS) were normalized against $\beta$-actin expression. To determine the relative quantification of gene expression, the comparative cycle of threshold $(\mathrm{Ct})$ method, with arithmetic formula $(2-\Delta \Delta \mathrm{Ct})$, was used.

\section{Histopathologic examination}

After being fixed with $10 \%$ buffered formalin and embedded in paraffin, brain samples were cut into 5-mm thick sections and then stained with hematoxylin-eosin (H\&E). Brain pathological injury was assessed via light microscope (Olympus BX51, Japan).

\section{TUNEL staining}

Rat brains were examined by a pathologist blinded to the groups. The TUNEL method (in situ apoptosis detection kit, Bio- 
gen, catalog no S7101) was used to identify and quantify apoptotic neuronal cells and to detect DNA fragmentation in neurons. The procedure was as follows:

1. Coronal brain sections, 5-mm thick, were deparaffinized and treated with alcohol.

2. Sections were incubated with protein kinase $\mathrm{K}$ at room temperature for $15 \mathrm{~min}$.

3. Sections were fixed in $4 \%$ paraformaldehyde phosphate-buffered saline (PBS) at room temperature for $30 \mathrm{~min}$,

4. Sections were washed three times with PBS.

5. The TUNEL reaction mixture was added to the sections and incubated in a humidified chamber with $50 \mu 1$ of terminal deoxynucleotidyl transferase (TdT) buffer in the dark for $1 \mathrm{~h}$ at $37^{\circ} \mathrm{C}$.
6. TUNEL labelled slides were counter-stained with $1 \%$ methyl green.

7. The reaction was stopped, and coverslips were mounted onto glass slides.

8. Apoptotic cells were counted in the hippocampus, subthalamic nucleus, and parietal cortex of the right hemisphere.

9. In evaluating the numeric density, total TUNEL-positive stained neurons were counted in five high power fields $(5 \times 400)$ under the light microscope (Olympus BX51, Japan).

\section{Statistical analysis}

Statistical analysis was conducted with SPSS (Statistical Package for Social Sciences, Chicago, IL, USA) 16.0 pocket program.
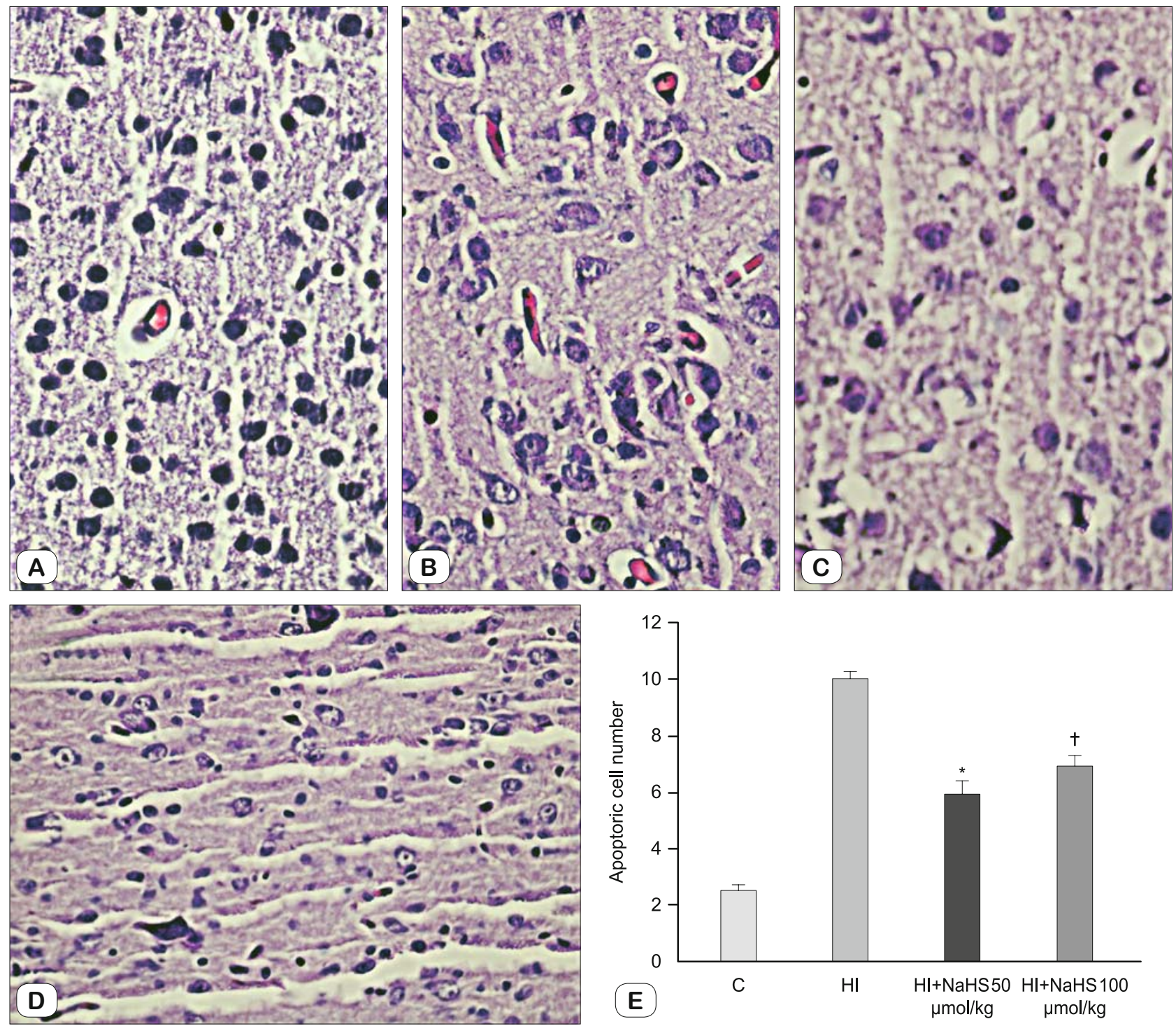

Fig. 2. Effect of NaHS on brain histopathologic examinations: Images are representatives of the H\&E-stained sections of the brain tissue from the experimental groups (H\&E staining). Original magnification: $\times 20$. A; C group, B; HI group, C; HI + NaHS $50 \mu \mathrm{mol} / \mathrm{kg}$ group, D; HI + $\mathrm{NaHS} 100 \mu \mathrm{mol} / \mathrm{kg}$ group, $\mathrm{E}$; * shows significant difference between $\mathrm{HI}$ and $\mathrm{HI}+\mathrm{NaHS} 50 \mu \mathrm{mol} / \mathrm{kg}$ groups $(\mathrm{p} \leq \mathbf{0 . 0 5}$; Mann-Whitney $\mathrm{U}$ test); $\dagger$ shows significant difference between $\mathrm{HI}$ and $\mathrm{HI}+\mathrm{NaHS} 100 \mu \mathrm{mol} / \mathrm{kg}$ groups $(\mathrm{p} \leq \mathbf{0 . 0 5}$; Mann-Whitney $\mathrm{U}$ test). 

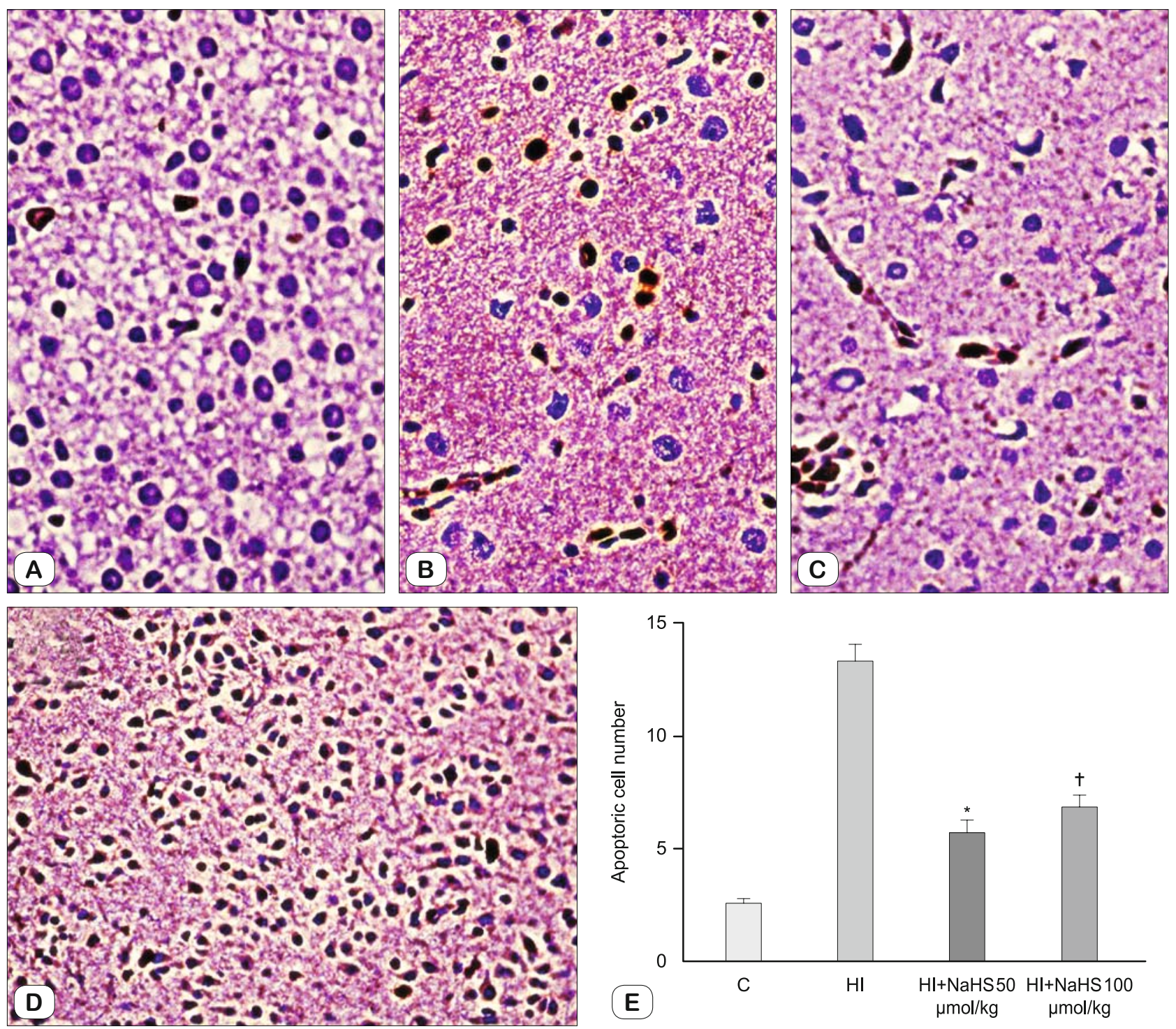

Fig. 3. Effect of NaHS on the number of TUNEL-positive apoptotic neurons: A; C group, B; HI group, C; HI + NaHS $50 \mu \mathrm{mol} / \mathrm{kg}$ group, D; HI + NaHS $100 \mu \mathrm{mol} / \mathrm{kg}$ group, E; * shows significant difference between $\mathrm{HI}$ and HI + NaHS $50 \mu \mathrm{mol} / \mathrm{kg}$ groups (p $\leq 0.05$ Mann-Whitney U test); $\dagger$ shows significant difference between $\mathrm{HI}$ and $\mathrm{HI}+\mathrm{NaHS} 100 \mu \mathrm{mol} / \mathrm{kg}$ groups $(\mathrm{p} \leq 0.05$; Mann-Whitney $\mathrm{U}$ test $)$.

All results were given as means \pm standard error (SE). Multiple groups were compared via Kruskal-Wallis test, while Mann-Whitney $U$ test was used to compare two groups. Values lower than $p$ $\leq 0.05$ were accepted as statistically significant.

Results

Effect of NaHS on tissue TAS, TOS and OSI levels

There were statistically significant differences in tissue TAS, TOS, and OSI levels among all the groups $(\mathrm{p}=0.04, \mathrm{p}=0.000$ and $p=0.03$, respectively) (Tab. 1). TAS levels were significantly increased in the $\mathrm{HI}+\mathrm{NaHS} 100 \mu \mathrm{mol} / \mathrm{kg}$ group as compared to $\mathrm{C}$ and HI groups $(\mathrm{p}=0.014, \mathrm{p}=0.04$, respectively). Tissue TOS levels of $\mathrm{HI}$ and $\mathrm{HI}+\mathrm{NaHS} 50 \mu \mathrm{mol} / \mathrm{kg}$ groups were significantly higher than those measured in the $\mathrm{C}$ group $(\mathrm{p}=0.000$ and $\mathrm{p}=$ 0.000 ). In addition, $100 \mu \mathrm{mol} / \mathrm{kg} \mathrm{NaHS}$ treatment showed significantly decreased TOS levels in the HI + NaHS $100 \mu \mathrm{mol} / \mathrm{kg}$ group as compared to the HI group $(\mathrm{p}=0.021)$. High levels of OSI were found in the HI group as compared with $\mathrm{C}, \mathrm{HI}+\mathrm{NaHS} 50 \mu \mathrm{mol} / \mathrm{kg}$, and $\mathrm{HI}+\mathrm{NaHS} 100 \mu \mathrm{mol} / \mathrm{kg}$ groups $(\mathrm{p}=0.027, \mathrm{p}=0.024$ and $\mathrm{p}=0.011$, respectively).

\section{Effect of NaHS on mRNA expression of TNF- $\alpha, I L-6, N G F$ and} iNOS

There were no significant differences in TNF- $\alpha$, IL-6, NGF, and iNOS gene mRNA expression levels in the brain tissues among $\mathrm{C}$, $\mathrm{HI}, \mathrm{HI}+\mathrm{NaHS} 50 \mu \mathrm{mol} / \mathrm{kg}$, and $\mathrm{HI}+\mathrm{NaHS} 100 \mu \mathrm{mol} / \mathrm{kg}$ groups $(p>0.05)$. Compared with the $\mathrm{C}$ group, plasma iNOS levels were 


\section{9-795}

decreased in $\mathrm{HI}+\mathrm{NaHS} 50 \mu \mathrm{mol} / \mathrm{kg}$ and $\mathrm{HI}+\mathrm{NaHS} 100 \mu \mathrm{mol} /$ $\mathrm{kg}$ groups, but this was not statistically significant. Expression levels of IL-6 and iNOS mRNA were increased in the HI group as compared to the $\mathrm{C}$ group $(\mathrm{p}=0.017, \mathrm{p}=0.05)$. Low levels of NGF gene mRNA expression were significant in the HI group as compared with HI + NaHS $50 \mu \mathrm{mol} / \mathrm{kg}$ and HI + NaHS $100 \mu \mathrm{mol} /$ $\operatorname{kg}$ groups $(\mathrm{p}=0.026$ and $\mathrm{p}=0.017)$ (Fig. 1$)$.

\section{Effect of NaHS on brain histopathologic examinations}

Based on histopathological analyses of the brains, normal histology was observed in the $\mathrm{C}$ group. There were no hemorrhages, neutrophils, leukocyte infiltrations, or neuron degenerations in this group. Numerous small hemorrhages, neutrophil leukocyte infiltrations, and increased numbers of degenerated neurons were observed in the HI group (Fig. 2). With routine hematoxylin eosin staining, apoptotic neurons showed round bounding, nuclear condensation, and cytoplasmic shrinkage as compared to neurons of normal morphology. Normal-looking neurons did not show positive staining with TUNEL, and most apoptotic cells were nuclearpositive with TUNEL. Apoptotic cell numbers were statistically significantly different among C $(2.5 \pm 0.16)$, HI $(10 \pm 0.21), \mathrm{HI}+$ $\mathrm{NaHS} 50 \mu \mathrm{mol} / \mathrm{kg}(5.9 \pm 0.45)$, and HI + NaHS $100 \mu \mathrm{mol} / \mathrm{kg}(6.9$ $\pm 0.34)(\mathrm{p}=0.000)$ groups with hematoxylin eosin staining. Compared with $\mathrm{HI}+\mathrm{NaHS} 50 \mu \mathrm{mol} / \mathrm{kg}$ and $\mathrm{HI}+\mathrm{NaHS} 100 \mu \mathrm{mol} / \mathrm{kg}$ groups, the apoptotic cell numbers were increased significantly in the HI group $(p=0.000$ and $p=0.000)$ (Fig. 2E).

\section{Effect of NaHS on the number of TUNEL-positive apoptotic neu- rons}

There were significantly more apoptotic cells in C (2.6 \pm 0.16$)$, $\mathrm{HI}(13.2 \pm 0.72), \mathrm{HI}+\mathrm{NaHS} 50 \mu \mathrm{mol} / \mathrm{kg}(5.7 \pm 0.64)$, and $\mathrm{HI}+$ NaHS $100 \mu \mathrm{mol} / \mathrm{kg}(6.9 \pm 0.43)$ groups with TUNEL staining (p $=0.000)$ (Fig. 3). The HI + NaHS $50 \mu \mathrm{mol} / \mathrm{kg}$ and HI + NaHS 100 $\mu \mathrm{mol} / \mathrm{kg}$ groups did not differ significantly in terms of apoptotic cell numbers $(p=0.43)$. However, the apoptotic cell numbers in $\mathrm{HI}+\mathrm{NaHS} 50 \mu \mathrm{mol} / \mathrm{kg}$ and $\mathrm{HI}+\mathrm{NaHS} 100 \mu \mathrm{mol} / \mathrm{kg}$ groups were significantly lower than in the HI group $(\mathrm{p}=0.000$ and $\mathrm{p}=0.000$, respectively) (Fig. 3E).

\section{Discussion}

Hypoxic ischemic encephalopathy is one of the main causes of neonatal deaths, cerebral palsy, mental retardation, and epilepsy after the neonatal period. $\mathrm{H} 2 \mathrm{~S}$ is a molecule known to play a protective role against ischemia reperfusion in cardiac, liver, kidney, and brain tissue through angiogenesis induction, vasodilatation, and regulation of neuronal activity and glucose metabolism $(11,14)$. $\mathrm{NaHS}$ is an $\mathrm{H} 2 \mathrm{~S}$ transmitter and can directly transform into H2S in serum. In this study, the antioxidant efficiency of $\mathrm{H} 2 \mathrm{~S}$ in rats with hypoxic ischemic encephalopathy formation was evaluated through intraperitoneal NaHS application at doses of $50 \mu \mathrm{mol} / \mathrm{kg}$ and $100 \mu \mathrm{mmol} / \mathrm{kg}$. The studies detected that inflammatory cytokines such as TNF- $\alpha$, are intensively released during the reperfusion period following hypoxia-ischemia. Yin Jun et al. examined the neuroprotective effects of NaHS (15), and a significant de- crease in TNF- $\alpha$ levels was detected in the $100 \mu \mathrm{mol} / \mathrm{kg}$ group as compared to the $50 \mu \mathrm{mol} / \mathrm{kg}$ group in ischemia-reperfusion damage among sampled rat brains. Again, in a study investigating the effects of NaHS on lipopolysaccharide-induced inflammation in microglial cell cultures, it was concluded that NaHS decreased TNF- $\alpha$ expression (16). Parallel to this study, the results acquired by the present researchers show that a decrease was observed in TNF- $\alpha$ mRNA gene expression level in the NaHS groups, but this was not statistically significant. Astrocytes are also the main inflammatory mediators producing IL-6. A model studying astrocyte efficiency against neuroinflammation in degenerative neurological diseases in cell cultures has shown that exogenous applications of H2S decreased the IL-6 expression (17). In the present study, a statistically insignificant decrease was detected in the IL-6 level compared to HI, HI + NaHS $50 \mu \mathrm{mol} / \mathrm{kg}$, and $\mathrm{HI}+\mathrm{NaHS} 100$ $\mu \mathrm{mol} / \mathrm{kg}$ groups.

Although in previous studies, many mechanisms of anti-inflammatory and antioxidant efficiency were not clearly identified while investigating the effects of NaHS, its antioxidant effects were emphasized. Such studies have also shown that this effect was provided by decreasing iNOS, SOD, MDA, and hydrogen peroxide $\left(\mathrm{H}_{2} \mathrm{O}_{2}\right)$ levels. In neonatal rats, it was shown that in the hypoxia-induced encephalopathy model, NaHS decreased both neuronal and inducible nitric oxide synthase mRNA expressions (18). Again, the neuroprotective effect of NaHS was checked; its antioxidant character was emphasized by decreasing oxidative stress; it was shown that NaHS given to rats with neuron damage related to oxygen-glucose-deficiency (OGD) inhibited MDA, NO, and $\mathrm{H}_{2} \mathrm{O}_{2}(19)$. Two studies conducted on rats with prenatal smoke exposure found that $\mathrm{NaHS}$ treatment healed neuronal chromatosis, functional disorder in central chemoreception, and Phox $2 \mathrm{~b}$ expression in the parafacial respiratory group ( $\mathrm{pFRG}$ ) region. They also detected that NaHS treatment stopped the decrease in glutathione levels occurring due to this effect in the medulla oblongata of neonatal rats. It also stopped the increase in malondialdehyde content and superoxide dismutase activity $(20,21)$. In another study, nicotinamide adenine dinucleotide phosphate (NADPH) oxidase (NOX) activity and antioxidant efficiency were evaluated in rats with medium cerebral artery occlusion and cerebral ischemia induction. They illustrated the antioxidant efficacy of NaHS by showing that it suppressed the enzyme activity of NOX, which is a reactive oxygen species (ROS) derivative, and thus strongly preserved the unity of the blood-brain barrier (22). Based on the antioxidant efficiency of NAHS in the present study, a significant increase in TAS levels, and a decrease in TOS and OSI levels were detected, especially in the $100 \mu \mathrm{mol} / \mathrm{kg} \mathrm{NaHS}$ group as compared to the HI group.

Although the antiapoptotic efficacy of NaHS has not yet been completely explained, a study of cell cultures showed that when caspase-3 was inhibited in the mitochondrial pathway of cell apoptosis, $\mathrm{H}_{2} \mathrm{~S}$ mediated the antiapoptotic effects (23). In another study examining the neuroprotective effects of NaHS against neurotoxicity induced by $\beta$ - amyloid peptide, numbers of apoptotic neurons were compared through the TUNEL method, and a significant decrease was detected in TUNEL-positive stained 
apoptotic neuron counts in the NaHS group (24). In the present study, the authors detected a decrease in apoptotic cell counts, both in low- and high-dose groups, and showed the anti-apoptotic efficacy of NaHS. A limited number of studies evaluating NGF levels to investigate the known neuroprotective effect of NaHS reported that NGF may provide this effect through angiogenesis, and NGF-stimulated retinal cells induced the multiplication of retinal neurons (25). The present authors considered that the significant increase in NGF gene mRNA expression levels in treated groups, as compared to the HI group, could be a demonstrator of the neuroprotective efficacy of NaHS.

\section{Conclusion}

This study has found that NaHS has an antioxidant effect by increasing TAS levels and decreasing TOS levels in the brain tissue of HIBH-induced neonatal rats. It has also shown some of the neuroprotective effects of NaHS by inducing NGF expression. This effect may be demonstrated through the antioxidant characteristics of NaHS and its ability to decrease apoptosis. Although some advancements have been achieved through this animal research concerning the molecular mechanisms of NaHS, which is an $\mathrm{H} 2 \mathrm{~S}$ transmitter, more research should be conducted, and clinical proof is required to better understand the role of $\mathrm{H}_{2} \mathrm{~S}$ in brain damage, especially during the reperfusion period.

\section{References}

1. Akisu M, Canpolat E. Neonatal Encephalopathy Diagnosis and Treatment Guidelines. Turk Neonatol Ass 2018; 1-39.

2. Jacobs SE, Berg M, Hunt R, Tarnow-Mordi WO, Inder TE, Davis PG. Cooling for newborns with hypoxic ischaemic encephalopathy. Cochrane Database Syst Rev 2013; 31; (1): CD003311.

3. Robertson NJ, Tan S, Groenendaal F et al. Which neuroprotective agents are ready for bench to bedside translation in the newborn infant? J Pediatr 2012; 160 (4): 544-552.

4. Kelen D, Robertson NJ. Experimental treatments for hypoxic ischaemic encephalopathy. Early Hum Dev 2010; 86 (6): 369-3.

5. Qipshidze N, Metreveli N, Mishra PK, Lominadze D, Tyagi SC. Hydrogen sulfide mitigates cardiac remodeling during myocardial infarction via improvement of angiogenesis. Int J Biol Sci 2012; 430-441.

6. Biermann J, Lagrèze WA, Schallner N, Schwer CI, Goebel U. Inhalative preconditioning with hydrogen sulfide attenuated apoptosis after retinal ischemia/reperfusion injury. Mol Vis 2011; 17: 1275-1286.

7. Rice JE, Vannucci RC. The influence of immaturity on hypoxic-ischemic brain damage in rat. Ann Neurol 1981; 9: 131-141.

8. Yin J, Zeng QH, Shen Q, Yang XS. Neuroprotective mechanism of hydrogen sulfide after cerebral ischemia-reperfusion in rats. Zhonghua Yi Xue Za Zhi 2013; 93 (11): 868-872.

9. Erel O. A novel automated direct measurement method for total antioxidant capacity using a new generation, more stable ABTS radical cation. Clin Biochem 2004; 37: 277-285.
10. Erel O. A new automated colorimetric method for measuring total oxidant status. Clin Biochem 2005; 38: 1103-1111.

11. Marutani E, Yamada M. Thiosulfate mediates cytoprotective effects of hydrogen sulfide against neuronal ischemia. J Am Heart Assoc 2015; $6 ; 4$ (11).

12. Papapetropoulos A, Pyriochou A, Altaany $Z$ et al. Hydrogen sulfide is an endogenous stimulator of angiogenesis. Proc Nat Acad Sci 2009; 106 (51): 21972-21977.

13. Kimura H. The physiological role of hydrogen sulfide and beyond. Biol Chem 2014; 41: 4-10.

14. Yang G, Wu L, Jiang B et al. H2S as a physiologic vasorelaxant: hypertension in mice with deletion of cystathionine $\gamma$-lyase. Science 2008; 322 (5901): 587-590.

15. Yin $\mathbf{J}$, Tu $\mathbf{C}$, Zhao $\mathbf{J}$ et al. Exogenous hydrogen sulfide protects against global cerebral ischemia/reperfusion injury via its antioxidative, anti-inflammatory and anti-apoptotic effects in rats. Brain Res 2013; 1491: 188-196.

16. Hu LF, Wong PT, Moore PK, Bian JS. Hydrogen sulfide attenuates lipopolysaccharide-induced inflammation by inhibition of p38 mitogenactivated protein kinase in microglia. J Neurochem 2007; 100: 1121-1128.

17. Lee M, McGeer EG, McGeer PL. Sodium thiosulfate attenuates glialmediated neuroinflammation in degenerative neurological diseases. J Neuroinflamm 2016; 8: 32.

18. Wang $Z$, Zhan J, Wang $X$ et al. Sodium hydrosulfide prevents hypoxia-induced behavioral impairment in neonatal mice. Brain Res 2013; 1538: $126-134$.

19. Yu Q, Wang B, Zhao $T$ et al. NaHS protects against the impairments induced by oxygen-glucose deprivation in different ages of primary hippocampal neurons. Front Cell Neurosci 2017; 7: 67.

20. Yan X, Lei F, Hu Y et al. Hydrogen sulfide protects neonatal rat medulla oblongata against prenatal cigarette smoke exposure via anti-oxidative and anti-inflammatory effects. 2018; 57: 151-158.

21. Yan X, Zhao F, Zhang S, Lei F, Wang W, Zheng Y. Hydrogen sulfide ameliorates disorders in the parafacial respiratory group region of neonatal rats caused by prenatal cigarette smoke exposure via an antioxidative effect. Environ Toxicol Pharmacol 2019; 68: 80-90.

22. Wang Y, Jia J, Ao G et al. Hydrogen sulfide protects blood-brain barrier integrity following cerebral ischemia. J Neurochem 2014; 129: 827-838.

23. Lin X, Yu S, Chen Y, Wu J, Zhao J, Zhao Y. Neuroprotective effects of diallyl sulfide against transient focal cerebral ischemia via anti-apoptosis in rats. Neurol Res 2012; 34 (1): 32-37.

24. Li XH, Deng YY, Li F, Shi JS, Gong QH. Neuroprotective effects of sodium hydrosulfide against $\beta$-amyloid-induced neurotoxicity. Int J Mol Med 2016; 38: 1152-1160.

25. Jadhao CS, Bhatwadekar AD, Jiang Y, Boulton ME, Steinle JJ, Grant MB. Nerve growth factor promotes endothelial progenitor cellmediated angiogenic responses. Invest Ophthalmol Vis Sci 2012; 53 (4): 2030-2037.

Received May 14, 2020. Accepted June 15, 2020. 